\title{
Overall Vibration Characteristics Calculation of a Fishery Administration Ship
}

\author{
Ji Wu ${ }^{1, a}$, Caogen Xiong ${ }^{1, b}$, Jun Long ${ }^{1, c}$ and Jinlong Bian ${ }^{2, d}$ \\ ${ }^{1}$ Dalian Scientific Test and Control Technology Institute, 16 Binhai Street. Dalian, 116013, China; \\ ²Dalian Shipbuilding Industry Group Co, Ltd. Dalian, 116011, China. \\ amewuji@126.com, bxiongcaogen@163.com, 'longjun3159@163.com, ddmubjl@163.com
}

Keywords: Fishery administration vessel, overall hull vibration, modal analysis, finite element method.

\begin{abstract}
To avoid resonance, suppress the hull vibration and reduce the noise, vibration characteristics must be predicted during the process of design. The added water mass of the fishery administration ship is calculated for predicting accurately the vibration characteristics. The natural frequency of vertical and horizontal vibration are calculated by FEM method and empirical formula method. The natural vibration characteristics of the target ship under no-load and full-load condition are calculated respectively. The natural frequency of 1st vertical and horizontal vibration which calculated by FEM and calculated by the empirical formula are similar. The natural frequency of the no-load condition is lower than the full load condition.
\end{abstract}

\section{Introduction}

In order to adapt to complex and volatile sea conditions, and to ensure the reliability and comfort of the ship operation, it is necessary to suppress the hull vibration and reduce the noise at the beginning of the design. The ship will be impacted by the main engine, propeller or the other external excitation, during the voyage. These external excitations will cause different level hull vibration, which may be harmful. Also, that may lead to fatigue damage of the structure, affect the normal use of the equipment and the work efficiency and health of the crews. Therefore, vibration characteristics must be calculated during the process of design. And then find the existing problems and put forward the solving measures, so as to avoid resonance and make the ship meet the requirements of low vibration and noise. This paper takes a 300 tons fishery administration ship as the research object, and studies the vibration characteristics with the finite element software ANSYS.

\section{Theoretical Analysis and Modeling}

\subsection{Calculation method of the added water mass.}

In order to more accurately predict the vibration characteristics, it is necessary to calculate the added water mass. The empirical formula method, the fluid finite element method and boundary element method are the mainly calculation method of ship added water mass. Based on the actual ship test, F. M. Lewis, F. H. Todd etc. puts forward the empirical formula used to calculate added water mass. To calculate the added water mass, the empirical formula method of Lewis is adopted. To calculate the vertical vibration of the ship, the formula of added water mass on the unit length is:

$$
m_{a v}=\frac{1}{2} \pi a_{v} C_{v} K_{v i} \rho b^{2}
$$

Where $\alpha_{v}, C_{v}, K_{v i}, \rho$ and $b$ are shallow water correction factor, the correction factors of vertical vibration for added mass, three-dimensional flow correction factors of vertical vibration for added water, water density $\left(\mathrm{t} / \mathrm{m}^{3}\right)$ and the half width of the waterline in rated section $(\mathrm{m})$.

In calculating the horizontal vibration of the ship, the formula of added water mass on the unit length is: 


$$
m_{a h}=\frac{1}{2} \pi a_{h} C_{h} K_{h i} \rho d^{2}
$$

Where $\alpha_{h}, C_{h}, K_{h i}, \rho$ and $d$ are marrow water correction factor, the correction factors of horizontal vibration for added mass, three-dimensional flow correction factors of horizontal vibration for added water, water density $\left(\mathrm{t} / \mathrm{m}^{3}\right)$ and the sea gauge in rated section $(\mathrm{m})$.

\subsection{D Modeling of the 300t fishery administration vessel.}

Three-dimensional modeling is constructed accurately to calculate added water mass of the $300 t$ fishery administration vessel. The main technical parameters of the $300 t$ fishery administration vessel are showed in table 1. As the structure is complex, three-dimensional model of the hull structure is established in Pro/E according to the design paper. 3D geometric model of the 300t fishery administration vessel is showed in Fig. 1. The element of shell 63, beam 188, solid 45 and fluid 30 are used in the integrated ANSYS meshing tool for meshing. The finite element model contains a total of 21364 shell elements, 19586 beam elements, 11768 elements, and 32717 nodes. The FEM of the 300t fishery administration vessel is showed in Fig.2.

Table 1 Main parameters of the 300t fishery administration vessel

\begin{tabular}{ccc}
\hline Parameter & Size & Unit \\
\hline Ship length & 49.9 & metre \\
Length between perpendiculars & 47.0 & metre \\
Molded breadth & 7.6 & metre \\
Moulded depth & 4.3 & metre \\
Frame space & 0.5 & metre \\
Mean draught of no-load condition & 2.1 & metre \\
Ligth displacement & 269.2 & ton \\
Full load displacement & 340.1 & ton \\
\hline
\end{tabular}

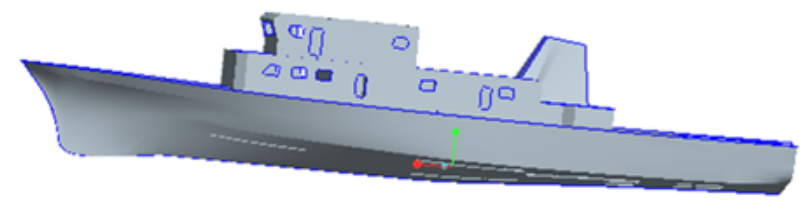

Side view

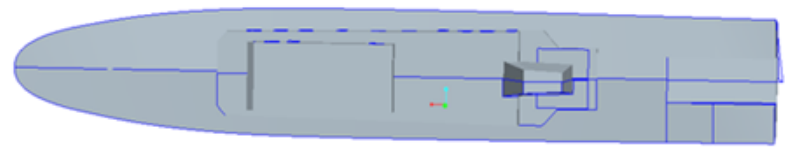

Vertical view

Fig. 1 Three-dimensional geometric model of the 300t fishery administration vessel

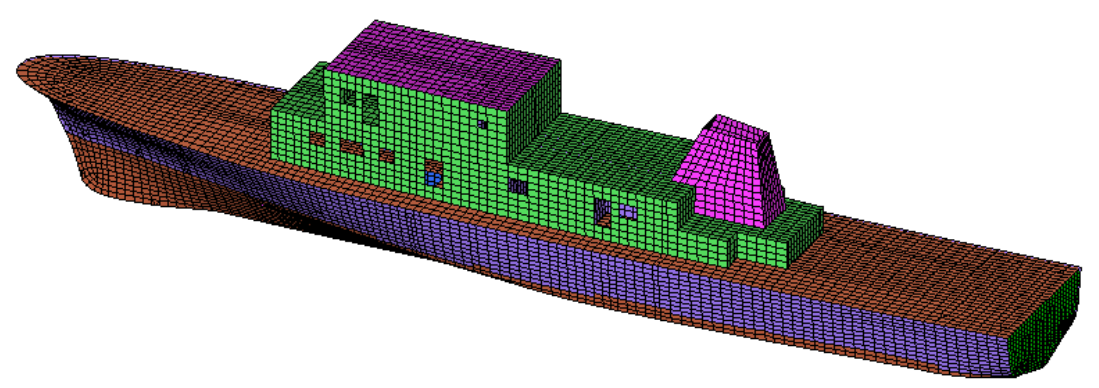

Fig.2 Finite element model of the 300t fishery administration vessel

\section{Calculation results analysis}

\subsection{Calculation of the added water mass}

Formula 1 and formula 2 are used to calculate the added water mass per unit length of each section. Reference ship vibration control guide of CCS, after calculating the added water mass of 21 segments, the average value of the added mass of the adjacent section is calculated. Finally, the added water mass of vertical and horizontal vibration are calculated. Based on the above method, the added water mass 
for no load and full load of first three order vertical and horizontal vibration are calculated and showed in Table 6.

Table 2. Added water mass of the $300 t$ fishery administration vessel

\begin{tabular}{ccccc}
\hline \multirow{2}{*}{ Order } & \multicolumn{2}{c}{ Added water mass of vertical vibration(ton) } & Added water mass of horizontal vibration(ton) \\
\cline { 2 - 5 } & No-load & Full-load & No-load & Full-load \\
\hline 1 & 383.3 & 412.1 & 340.1 & 421.8 \\
2 & 347.4 & 373.5 & 330.8 & 410.4 \\
3 & 314.6 & 338.3 & 323.1 & 400.7 \\
\hline
\end{tabular}

\subsection{Modal analysis}

As a free elastomer floating on the sea in this research, the modal analysis of the 300t fishery administration vessel is obtained without imposing any boundary conditions, that is, free modal analysis. After loading added water mass and effective mass, the natural frequency of the ship is calculated in ANSYS.

In this paper, the natural vibration characteristics of the target ship under no-load and full-load condition are calculated respectively. The natural frequency of vertical and horizontal vibration are calculated by FEM method and empirical formula method. The natural mode of vibration under no-load condition in first two order natural frequency is showed in Fig. 3. The natural mode of vibration under full-load condition in first two order natural frequency is showed in Fig. 4. Table 3 showed natural frequency comparison between estimate calculation formula and FEM. It proves the reliability and validity of the FEM model in this paper. The natural frequency of the full-load condition is lower than the no-load condition. For the increasing of the mass of ship's vibration and constant stiffness, the natural frequency for full load is reduced.

Table 3. Natural frequency comparison between empirical formula and FEM

\begin{tabular}{ccccc}
\hline & \multicolumn{2}{c}{ No-load condition } & \multicolumn{2}{c}{ Full-load condition } \\
\cline { 2 - 5 } & estimate formula & FEM & estimate formula & FEM \\
\hline $1^{\text {st }}$ vertical vibration & 4.481 & 4.621 & 4.229 & 4.460 \\
$2^{\text {nd }}$ vertical vibration & 7.379 & 7.845 & 6.961 & 7.699 \\
$1^{\text {st }}$ horizontal vibration & 6.570 & 5.897 & 5.934 & 5.181 \\
$2^{\text {nd }}$ horizontal vibration & 13.862 & 9.749 & 12.533 & 8.823 \\
\hline
\end{tabular}

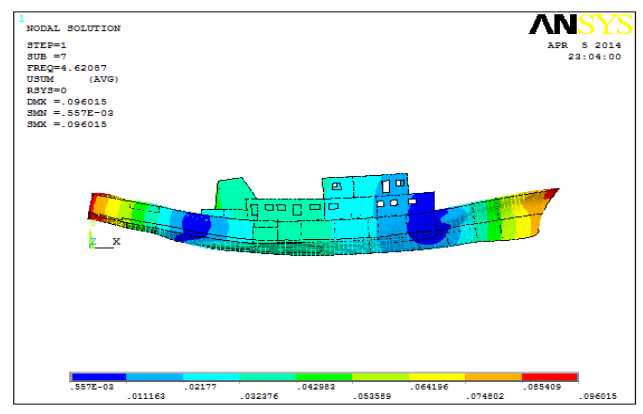

(1) 1st vertical vibration

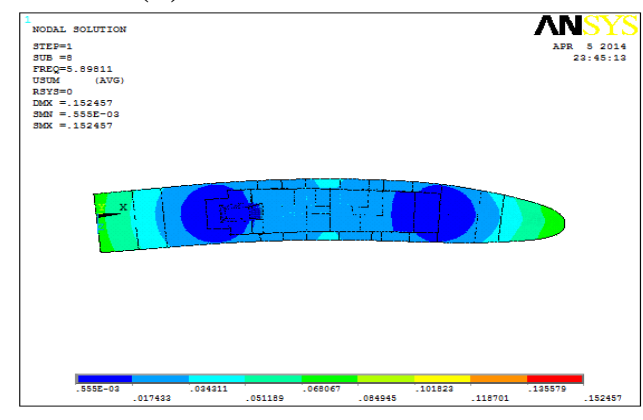

(3) $1^{\text {st }}$ horizontal vibration

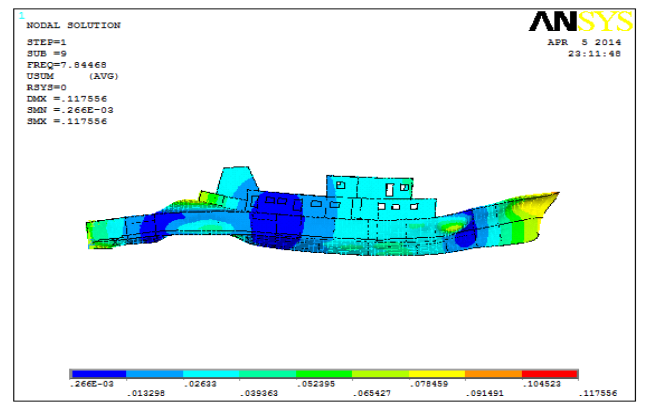

(2) $2^{\text {nd }}$ vertical vibration

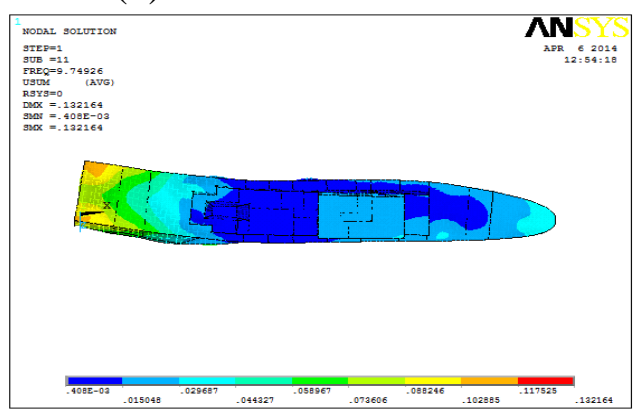

(4) $2^{\text {nd }}$ horizontal vibration

Fig. 3 Vibration mode of no-load condition 


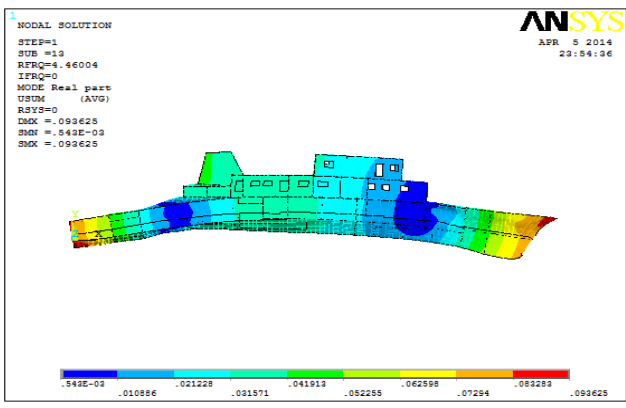

(1) 1st vertical vibration

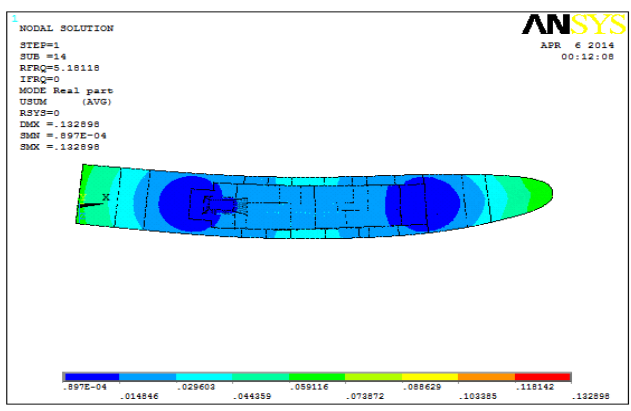

(3) $1^{\text {st }}$ horizontal vibration

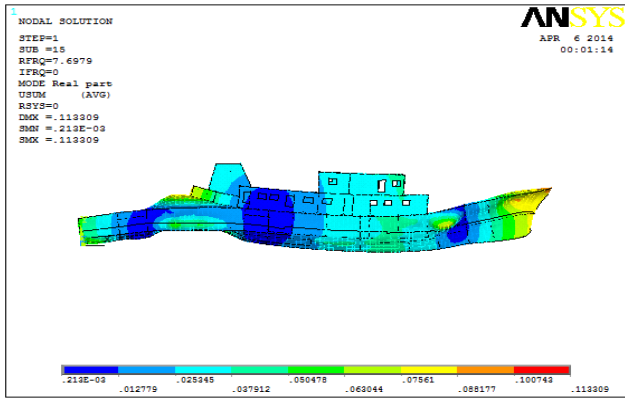

(2) $2^{\text {nd }}$ vertical vibration

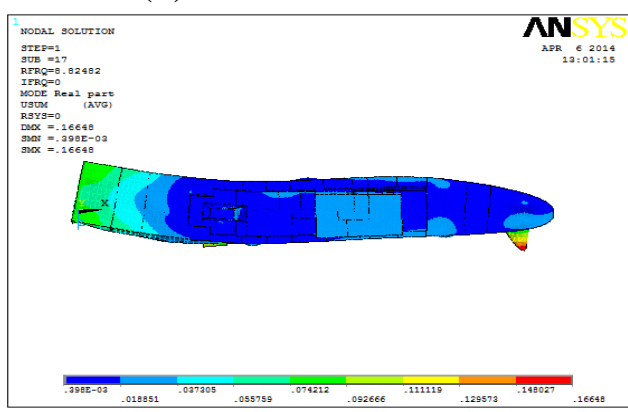

(4) $2^{\text {nd }}$ horizontal vibration

Fig.4 Vibration mode of full-load condition

\section{Summary}

The main conclusions drawn from the results of this study are listed as follows:

(1)The added water mass of full load is greater than the no-load condition.

(2) The natural frequency of the full-load condition is lower than the no-load condition. For the increasing of the mass of ship's vibration and constant stiffness, the natural frequency for full load is reduced.

(3) The natural frequency of 1 st vertical and horizontal vibration which calculated by FEM and calculated by the empirical formula are similar. It proves the reliability and validity of the FEM model in this paper.

\section{References}

[1]. Muthuveerappan G, Ganesan N, Veluswami M A. Influence of fluid added mass on the vibration characteristics of plates under various boundary conditions. Journal of Sound \& Vibration. No. 69(1980) No.4, p. 612-615.

[2]. Yin Y M, Cui H Y, Hong M, et al. Prediction of the vertical vibration of ship hull based on grey relational analysis and SVM method. Journal of Marine Science and Technology. Vol. 20(2015) No. 3, p. 467-474.

[3]. Yin Y, Zhao D, Cui H, et al. PREDICTING METHOD OF NATURAL FREQUENCY FOR SHIP'S OVERALL VERTICAL VIBRATION. Brodogradnja. Vol. 65 (2014) No. 3, p. 49-58.

[4]. Wu J S, Hsieh M. An experimental method for determining the frequency-dependent added mass and added mass moment of inertia for a floating body in heave and pitch motions. Ocean Engineering. Vol. 28(2001) No. 4, p. 417-438.

[5]. Jiang D Z, Hong M, Zhou L. Application of Operational Modal Analysis in Vibration of Ship Structures [J]. Chinese Journal of Ship Research, 2010, 54(4):2922-36.

[6]. CCS. Ship vibration control guide. China Communications Press, 2012, p. 149-165. 